\title{
A stochastic approach for measuring the uncertainty of claims
} reserves $^{\star}$

\author{
Bruno Domingues Ramos de Carvalho' \\ (D) https://orcid.org/0000-0002-7984-7145 \\ Email: bruno.domingues.carvalho@hotmail.com
}

João Vinícius de França Carvalho'

(D) https://orcid.org/0000-0002-1076-662X

Email: jvfcarvalho@usp.br

\author{
${ }^{1}$ Universidade de São Paulo, Faculdade de Economia, Administração e Contabilidade, Departamento de Contabilidade e Atuária, São Paulo, SP, \\ Brazil
}

Received on 03.25.2018 - Desk acceptance on 04.10.2018 - $2^{\text {nd }}$ version approved on 02.22.2019 - Ahead of print on 06.27.2019

Associate Editor: Luís Eduardo Afonso

\begin{abstract}
This paper aims to obtain metrics for quantifying the variability of technical provisions for claims by making use of deterministic and stochastic models. In short, everything that the traditional methods do not provide (measures of variability and capital insufficiency) are of fundamental importance for efficient actuarial management. The proposed methodology reveals the probability of insufficiency of the allocated capital to cover the commitments assumed by the insurer. In order to maintain resources to cover the indemnities payable to the insured, insurance companies include technical provisions in their balance sheets. Technical provisions are estimates and are therefore a source of fluctuations in the profit and loss statement of insurers, so understanding and protecting against these adverse variations is fundamental for efficient actuarial management. The stochastic approach enables internal models to be studied for solvency capital, which is a subject that lacks studies in the Brazilian market, and which is determined by a standard model pre-defined by the regulatory body. Stochastic modeling was proposed for Incurred But Not Reported Reserve using bootstrapping and, to validate this approach, the results were compared with the traditional approaches using real Motor Hull and Motor Third Part Liability data from a Brazilian insurance company. There are advantages of adopting stochastic methods instead of deterministic ones to determine technical provisions for claims, since it is possible to empirically estimate the probability distributions. The quantiles of these curves reveal the estimated probability of the real value exceeding a particular level of provisioning in order to extract the probability of capital shortage that the traditional methods do not provide. In addition, the results show that the traditional methods are too conservative, allocating more capital than necessary.
\end{abstract}

Keywords: technical provisions, IBNR, estimating insurance liabilities, chain ladder, stochastic modeling, bootstrapping.

Correspondence address

Bruno Domingues Ramos de Carvalho

Universidade de São Paulo, Faculdade de Economia, Administração e Contabilidade, Departamento de Contabilidade e Atuária

Avenida Professor Luciano Gualberto, 908 - CEP 05508-010

Cidade Universitária - São Paulo - SP - Brazil

*Article presented at the XVII USP International Conference in Accounting, São Paulo, SP, Brazil, July 2017. 


\section{INTRODUCTION}

In insurance companies, whose core business is underwriting risks, technical provisions represent the main component of their liabilities. Accurately calculating technical provisions has a direct impact on income distribution and the amount of tax payable, as well as being a particular object of analysis in merger and acquisition situations, since excessive reserves are a burden on present operating profit, as establishing a reserve generates an accounting expense. In contrast, setting a lower reserve than should be established exposes the entity to a greater probability of insolvency, thus affecting its credibility in the market.

Roughly speaking, technical provisions are divided into two groups: premiums reserves and claims reserves. The differentiation derives from the temporal perspective, since premiums reserves are constituted to cover the claims that are expected to occur and their respective expenses (future events), while claims reserves are values calculated to cover indemnities and expenses associated with claims that have already occurred (past events).

Liabilities relating to future events have two components: unearned premiums reserves (UPR) and UPR for in force unissued risks (UPR-IUR). Claims reserves are segregated into outstanding claims reserves (OCR) and incurred but not reported (IBNR) claims reserves. These reserves can also be segregated according to the way they are calculated, between exact and estimated reserves. According to Brazilian Institute of Actuaries (Instituto Brasileiro de Atuária - IBA) Resolution n. 5/2014, UPR-IUR, OCR, and IBNR are considered to be estimated reserves, and UPR is considered to be a reserve that is exact in nature.

Estimated reserves are calculated using actuarial and statistical methodologies and should reflect the best estimate of the entity's responsibility to its insured in terms of future commitments. OCR is calculated individually for each claim or according to the estimated loss for when the insured party takes legal action against the insurer to indemnify them and can also be altered due to reevaluations of the value of the final indemnities. UPR-IUR and IBNR reserves are usually calculated using the chain ladder method, using the run-off triangles technique, which indicates the development of reported claims or the issuing of policies over time. However, this method only establishes a point estimate of technical provisions for accounting purposes, which is insufficient for the actuarial analyst or any other information user to understand the possible fluctuations in the technical provisions and their impacts on the entity's profit and loss statement (P\&L), as well as on the balance sheet. Thus, it is the job of the actuary responsible for the company to correctly calculate these liabilities and it is the responsibility of the independent actuarial auditor to provide an opinion on the reasonableness of these values, offering the best predictability of future results to the stakeholders.

In this context, this paper has two main objectives: (i) to obtain a measure of variability for claims reserves estimated using the chain ladder method in order to construct a confidence interval for the Best Estimate of the technical provision, providing additional parameters for actuarial decision making; and (ii) to evaluate in what way adopting stochastic models can generate additional information about the behavior of claims reserves. Thus, the central questions that the paper aims to answer are: (i) how should a confidence interval be determined for estimating technical provisions for claims? (ii) what are the benefits of the stochastic approach in the analysis of technical provisions?

Mano and Pereira (2009) classify claims reserves into two categories: reserves for "known claims" and for "unknown claims". Reserves for known claims are OCR and reserves for unknown claims are IBNR. The object of study of the paper will be reserves for unknown claims, namely IBNR, which covers two components that are different in nature: incurred but not yet reported (IBNyR) claims reserves and incurred but not enough reported (IBNeR) claims reserves, which correspond to the estimate from reevaluations of the amount of indemnifiable claims. All these components aim to estimate the overall incurred but not paid (IBNP) claims reserve, whose relationship with the reserves is given by equation 1 below.

$$
I B N P=O C R+I B N y R+I B N e R .
$$

To show the relevance of this topic, Figure 1 presents the evolution of the amount of premiums reserves and claims reserves between 2009 and 2015 (left vertical axis) and their relationship with market growth, represented by the premiums issued (right vertical axis). Table 1 presents the balance of premiums reserves and claims reserves of the Brazilian insurance market on December $31^{\text {st }}$ of 2015 (in constant values). 

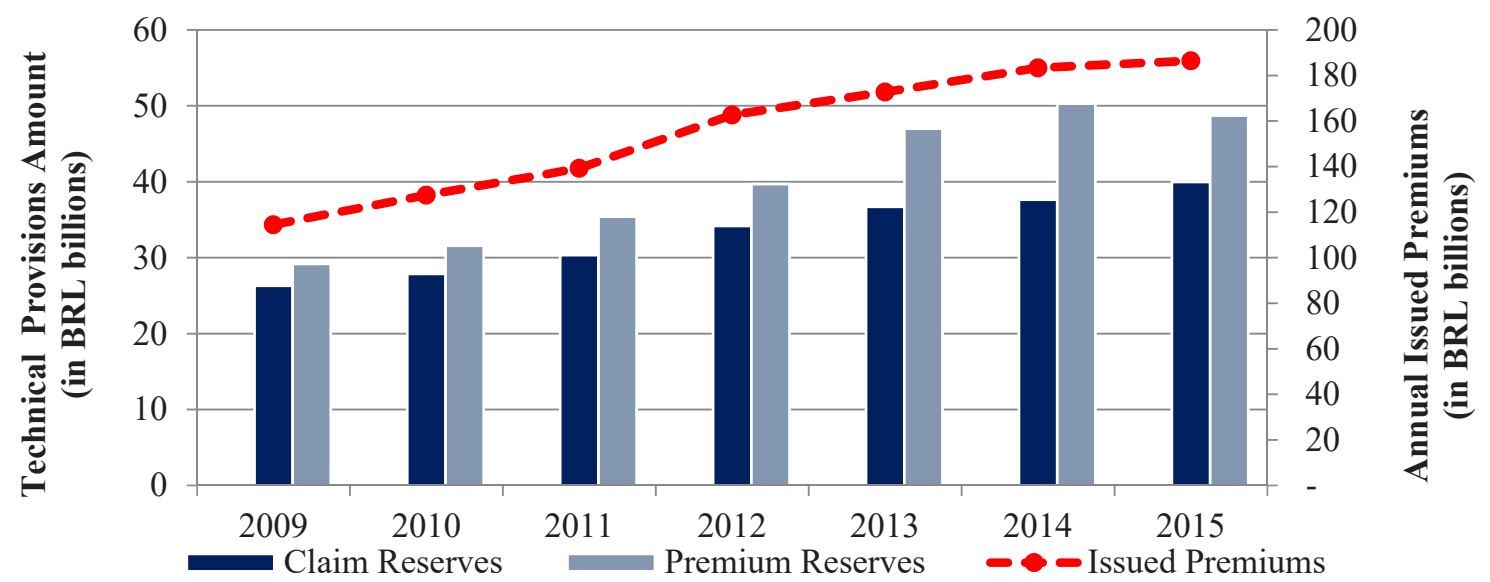

Figure 1 Evolution of premiums and claims technical reserves and premiums issued

Source: Elaborated by the authors with data from the Statistical System of the Superintendence of Private Insurance (SUSEP).

Table 1

Composition of the balance of technical provisions of the Brazilian insurance market on December $31^{\text {st }}$ of 2015

\begin{tabular}{ccc}
\hline Description & $\begin{array}{c}\text { Balance on } \\
\mathbf{1 2 / 3 1 / 2 0 1 5} \\
\text { (BRL billion) }\end{array}$ & $\begin{array}{c}\text { Relevance in relation } \\
\text { to total reserves } \\
\text { (\%) }\end{array}$ \\
\hline Total reserves & 87,859 & 100 \\
\hline Of premiums & 48,268 & 55 \\
\hline UPR & 45,449 & 52 \\
\hline UPR-IUR & 2,819 & 3 \\
\hline Of claims & 39,592 & 45 \\
\hline OCR & 29,689 & 34 \\
\hline IBNR & 9,902 & 11 \\
\hline
\end{tabular}

$I B N R=$ incurred but not reported; UPR = unearned premiums reserves; UPR-IUR = UPR for in force unissued risks; OCR = outstanding claims reserves.

Source: Elaborated by the authors with data from the Statistical System of the Superintendence of Private Insurance (SUSEP).

According to the information contained in Table 1 and in Figure 1, the Brazilian insurance market presented expressive real growth in the period, with a $63 \%$ increase in the volume of premiums issued between 2009 and
2015, discounting official inflation [Extended National Consumer Price Index (Índice Nacional de Preços ao Consumidor Amplo - IPCA)]. To cover the risks assumed by the entities, the volume of technical provisions has accompanied this growth. It should be mentioned that all the values ignore the operations of local reinsurers, capitalization companies, and the mathematical reserves for the insurance of people in cash value life insurance (Vida Gerador de Benefícios Livres - VGBL) and private pension plans (Plano Gerador de Benefícios Livres PGBL), given that these operations are subject to different risk factors from those that damage insurance is subject to, and so, therefore, are the calculation methods and techniques used.

This paper is divided into four more sections besides this introduction. In the next section a brief review of the literature and of the regulatory framework regarding the topic is carried out. In the third section, the deterministic and stochastic methodological procedures for estimating IBNR are presented. In section 4 the results obtained using the simulations are analyzed. Finally, section 5 provides the conclusions of the study and its limitations, as well as suggestions for future research.

\section{THEORETICAL BACKGROUND AND REGULATORY FRAMEWORK}

In the international context, the Actuarial Standards Board (ASB) $(2010,2011)$, an organ formed of members of the American Academy of Actuaries and other U.S. actuarial entities, offers guidance to actuaries for executing work that requires actuarial opinions to fulfill the requirements of accounting rules such as the International Financial Reporting Standards (IFRS) and
United States Generally Accepted Accounting Principles (US GAAP), among others.

In Actuarial Standard of Practice n. 36 - Statements of actuarial opinion regarding property/casualty loss and loss adjustment expense reserves (ASOP 36), the ASB (2010) provides guidance for the actuary when issuing an actuarial opinion regarding claims reserves for damage 
insurance operations. This guidance highlights that, when developing estimates for claims reserves, the actuary should develop a point estimate, an interval of estimates, or both, to evaluate the reasonableness of the reserve amount.

In addition to the guidelines of ASOP 36, in Actuarial Standard of Practice n. 43 - Property/casualty unpaid claim estimates (ASOP 43), the ASB (2011) provides guidance for the work of actuaries when calculating claims reserves and defines the final result of the actuary's calculation process as the Actuarial Central Estimate, that is, an estimate that represents the expected value in an interval of reasonably possible results. To obtain the Actuarial Central Estimate and the Reasonable Reserve Estimate Range, the ASB recommends for the actuary to use methods or models for estimating claims reserves that are appropriate for the operations of the entity under analysis, according to the actuary's judgement.

Also in the international context, the Solvency II agreement of the European Union (governed by Directive of the European Commission n. 139/2009) came into effect in 2016, establishing the basic criteria for constituting technical provisions within the context of the European Union for reducing insolvency risk in insurance companies. It was established by the agreement that reserves should represent the best estimate of the expected value of discounted cash flows, considering reliable data, realistic premises, and their being calculated using appropriate, applicable, and relevant actuarial and statistical methods, In addition, Dreksler et al. (2015) states that, under the lens of Solvency II, technical provisions should represent the best estimate of current liabilities related to the insurance policies plus a margin of risk.

The Brazilian legislation that addresses the constitution of technical provisions is represented by Superintendence of Private Insurance (Superintendência de Seguros Privados - SUSEP) Bulletin n. 517/2015, supported by the Normative Guidelines published by SUSEP on its website. According to this standard and the guidelines for it, entities should develop statistical methods for calculating estimated reserves that are appropriate for the characteristics of their operations, consistent with the events observed, and should be duly recorded in supporting documentation elaborated by the technical actuary responsible.

The independent actuarial audit is a recent topic in the Brazil market. In 2014, National Council of Private Insurance (Conselho Nacional de Seguros Privados - CNSP) Resolution n. 311/2014 was published, which required entities to hire actuarial auditors that issue reports - to be published in the annual financial statements, together with the auditors' report in the financial statements - regarding technical provisions, reinsurance assets, minimum capital required, retention limits, and reinsurance operations of companies supervised by SUSEP. Currently, the services of the independent actuarial auditor are regulated by CNSP Resolution n. 32/2014 and by IBA Resolution n. $5 / 2014$, which establish the procedures to be carried out for obtaining evidence that supports the auditor's conclusions.

Regarding the scope of analysis of technical provisions for claims, the standard determines that the actuarial auditor should evaluate the suitability of the constitution of the technical provisions, verifying that the methodologies adopted by the entities respect the normative criteria established by SUSEP and executing procedures for consistency tests and independent recalculations for the estimated reserves, with the aim of evaluating the quality of the estimates and whether there are indications that the values calculated do not reflect the reality of the business.

It is therefore noted that there is a convergence of requirements both in the international and in the Brazilian legislation, in which both suggest that the reserves should be estimated by applying adequate methods and models that are consistent with the reality of the insurers and that therefore generate reasonable estimates. However, terms such as "consistency", "adequacy", "reasonableness", and "best estimate" are relative, subjective, and liable to interpretation.

In this context, Shapland (2003) resorts to some definitions of ASOP 36 and develops a more concise framework for defining the term "reasonable reserve estimate", proposing statistical principles that actuaries can include in their claims reserves analysis. The author presents a review of various metrics for quantifying risk, including the model proposed by Mack (1993). The main conclusions of this paper indicate some of the benefits of using probabilistic approaches, such as: (i) the use of probabilistic models provides more inputs for quantifying risks and taking strategic decisions; (ii) the concept of materiality, used for decision making in auditing, may be better related to the uncertainties of the reserve estimates; (iii) the calculation of additional capital based on risk may be associated with the "level" of probability of the reserves; and (iv) the concept of margin of prudence for a reserve may be related to a portion of the probability interval, which is associated with the uncertainties of the reserve estimates.

The work of Shapland (2003) reveals the relevance of the stochastic models from the 2000s onwards. From a historical perspective, it is verified that the first algorithms applied to the claims reserving process date back to the 1930s, with the work of Tarbell (1934). According to Taylor and McGuire (2016), the chain ladder method was used for the first time in the 1950s by a small insurance 
company called Midwestern Insurance Company. Years later, Bornhuetter and Ferguson (1972) introduced a method based on exposure measures and expected loss indicators, and this procedure may be used together with chain ladder methods to obtain the final claims estimate.

However, up to that point, the methods were no more than simple deterministic algorithms for obtaining point estimates. Hachemeister and Stanard (1975) made significant advancements on this question by defining a stochastic model of claims data for which the chain ladder method presented a maximum likelihood. Then, from the 1990s onwards, with the advancement of computational technology, it was possible to study the inclusion of variability measures in the models. Here, one relevant paper is that of Mack (1993); with its standard error estimates for claims reserves calculated using chain ladder, it is considered to be a stochastic model that is free of probability distributions.

Currently, the empirical literature has been concentrating its efforts on studying stochastic approaches for fulfilling regulatory requirements, mainly geared towards the requirements of the Solvency II agreement with regards to internal models, as well as in experiments with modeling using generalized linear models (GLM) to estimate the parameters associated with the probability distributions of claims reserves. The paper by England and Verrall (2002) stands out, which provides a set of stochastic approaches that are applicable to claims reserves. The study covers models that range from reproducing the estimates obtained using the chain ladder method to parametric curve and development pattern smoothing models, as well as models based on dynamic financial analysis (DFA). Also in this paper, the studies by Bornhuetter and Ferguson (1972) are reviewed, but with the addition of an approach based on Bayesian inference. The conclusions of the paper indicate that one of the main advantages of stochastic modeling is the obtainment of metrics regarding the precision of the estimates.

England and Verrall (2006) extend the study to some of the models presented by England and Verrall (2002) and show how claims reserve distributions can be obtained using bootstrapping and Bayesian techniques. The text describes the bootstrapping iterative procedure and implements a Bayesian model using Markov chains and Monte Carlo simulation. These results were then compared and it was shown that, under the same premises, these models generate similar estimates. The study concludes that the main advantage of these approaches is the automatic generation of complete predictive distributions, which are essential for building internal models of riskbased additional capital.
Schiegl (2015) developed a 3D stochastic model, based on the theory of collective risk, which works on the dimensions of occurrence periods ( $i$ ), report development periods $(j)$, and development periods for claims liquidation status after they are reported $(k)$. The aim is to model the number of active (not fully paid) claims, as well as the amount payable relating to these claims. The reserves estimated by these models were then compared with the results obtained using chain ladder (2D). The results obtained reveal that the reserves calculated by the $3 \mathrm{D}$ model coincide with those estimated using chain ladder. This coincidence demonstrates that the third dimension used - claim liquidation status - does not influence the results of the 2D model structured only in the occurrence and development period dimensions.

Most of the previously described stochastic models group data into triangles. According to Schmidt (2006), the use of run-off triangles - the structural form of the data for applying the chain ladder method - in the process of reserving claims is justified by the premise that the development of the claims for all the occurrence periods follows a particular pattern; that is, the past behavior of the claim amounts can be used to estimate their future evolution. For him, this premise can be understood as a primitive stochastic model for the claims reserving process.

However, this method is subject to some constraints. For Weindorfer (2012), the premise that past behavior is the source of data for predicting future events should be taken with caution, since a basic requirement for using past experience to estimate the future is that the data involved in the prediction are precise and free of errors. In addition, the insurer should ensure that its own experience does not contradict the fundamental premise of the chain ladder method. For example, some reasons for which claim payment patterns are affected include: alterations in general conditions in the design of products; changes in the temporal lag between the occurrence of a claim and the receipt of the respective notice by the entity; alterations in the regulation process for claims and, consequently, in their financial settlement process; alterations introduced by regulatory rules; and the occurrence of atypical cases of claim payments with very high values (catastrophes) or very low values (claims barely above the deductible portion).

According to research carried out by the International Actuarial Association (IAA, 2016), which collected data from 535 entities in 42 countries, regarding deterministic methodologies, chain ladder is the most globally used method for calculating claims reserves. Around 95\% of the insurance companies researched use it. In next place is the Bornhuetter and Ferguson (1972) method, 
used by $90 \%$ of the companies. Regarding the stochastic methods, Mack and bootstrapping stand out, and are used by around $45 \%$ of the entities.

In Brazil, 34 insurers were researched and 97\% adopt chain ladder as a main or alternative method. The
Bornhuetter and Ferguson (1972) method is used by $74 \%$ of the entities. The study reveals that only around $20 \%$ of Brazilian insurers use stochastic approaches and, when they do, these are only informative and do not influence the decision making process regarding reserve amounts.

\section{METHODOLOGICAL PROCEDURES}

Based on the claims movement data, recorded in the statistical tables sent to SUSEP by one particular insurer for Motor Hull and Motor Third Part Liability (MTPL) insurance portfolios, in the period between January of 2010 and December of 2015, the IBNR reserve was reestimated for the December $31^{\text {st }}$ of 2015 base date, using the chain ladder and Bornhuetter and Ferguson (1972) methods. The calculations were made considering reported claim values gross of expenses and reinsurance recoveries.

Next, using the model described by Mack (1993), the standard error associated with the reserve will be estimated and, having obtained this standard error, a confidence interval of estimates is established. Empirical probability distributions for the IBNR reserve obtained using bootstrapping are also studied, considering 10 thousand simulations. Finally, the results for the deterministic interval and the empirical distributions are compared and discussed.

Weindorfer (2012) lists the following stages for applying the chain ladder method: (i) group the claims data into run-off triangles; (ii) calculate the development patterns; (iii) estimate the final claims amount using the result from stage (ii); and (iv) estimate the claims reserve. Next, the description of each one of these stages is presented.

Adopting the notation defined by Mack (1993), let $C_{i, k}$ be the total amount of cumulative claims for occurrence period $i$, where $1 \leq i \leq n$, reported $k$ periods after the occurrence period, with $1 \leq k \leq n$ (development period) and $\mathrm{k}=1,2, \ldots, n$.

$C_{i, k}$ is thus considered to be an observed random variable if $i+k \leq n+1$. This is the formal definition of the run-off triangle of cumulative claims. When grouped, these data form the following square matrix $I_{n \times n}$ :

$$
I_{n x n}=\left[\begin{array}{cccccc}
C_{1,1} & C_{1,2} & \ldots & C_{1, n-2} & C_{1, n-1} & C_{1, n} \\
C_{2,1} & C_{2,2} & \ldots & C_{2, n-2} & C_{2, n-1} & \\
C_{3,1} & C_{3,2} & \ldots & C_{3, n-2} & & \\
\vdots & \vdots & \ddots & & & \\
C_{n-1,1} & C_{n-1,2} & & & & \\
C_{n, 1} & & & & &
\end{array}\right],
$$

in which the arrows indicate the temporal direction of the data, from the oldest to the most recent.
The aim of the chain ladder method is to estimate the final amount of reported claims $C_{i, n}$ and the respective claims reserves

$$
R_{i}=C_{i, n}-C_{i, n+1-i}
$$

for each occurrence period $i=0,1,2, \ldots, n$.

The basic premises of the method are:

I. There are development factors $f_{1}, f_{2}, \ldots, f_{\mathrm{n}-1}>0$ such that $E\left(C_{i, k+1} \mid C_{i, 1}, \ldots C_{i, k}\right)=C_{i, k} f_{k}, 1 \leq \mathrm{i} \leq \mathrm{n}, 1 \leq \mathrm{k} \leq \mathrm{n}-1$. This formulation describes a Markov chain, that is, a stochastic process in which the probability and expectation for future events depends only on the information contained in the past.

II. $\left\{C_{i, 1}, \ldots, C_{i, n}\right\},\left\{C_{j, 1}, \ldots, C_{j, n}\right\}, i \neq j$ are independent; that is, the method assumes that there is no dependency relationship between the cumulative amounts of claims from different occurrence periods.

Note that the sum of the terms of the secondary diagonal of matrix $I_{n x n}$ corresponds to the known amount of the reported claims up to period " $n$ ". That is:

$$
C_{i, n+1-i}=C_{n, 1}+C_{n-1,2}+\ldots+C_{3, n-2}+C_{2, n-1}+C_{1, n} .
$$

Based on this matrix, factors are calculated that measure the relative development of the cumulative amount of claims between one development period and the following period. These factors form the basis for selecting the development patterns that will be used to project the final amount of reported claims, $C_{i, n+1-i}$. These factors are given by the ratio:

$$
f_{i, k}=\frac{C_{i, k+1}}{C_{i, k}} .
$$

These factors can then be grouped in the square matrix $F_{(n-1) x(n-1)}$ :

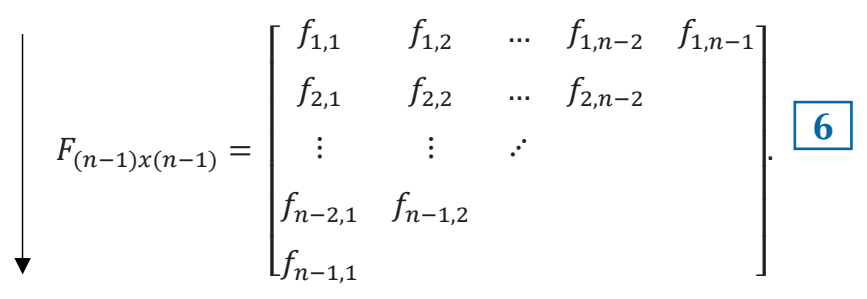


Having obtained this matrix, in order to determine the unique estimator that represents the development pattern for each period $\mathrm{k}, f_{k}$ is estimated, which is a central measure of the ratio of growth of the cumulative amount of reported claims. Due to its good statistical properties, the weighted average of the development factors is the choice indicated for $f_{k}$. However, the adherence of this development pattern should be periodically tested using consistency tests that compare the calculated values of the reserve on past dates with the effectively observed data, considering the most recent data available.

After choosing the development patterns $f_{k}$, these should be accumulated in the following way:

$$
\hat{f}_{k}=\prod_{k=1}^{n} f_{k} .
$$

The $\hat{f}_{k}$ factors enable the final amount of reported claims for each occurrence period $i$ to be estimated using equation 8 below:

$$
C_{i, n}=C_{i, n+1-i} \cdot \hat{f}_{k}, i=0,1,2, \ldots, n .
$$

Finally, the IBNR reserve, denoted here by $\hat{R}$, will be given by:

$$
\widehat{R}=\sum_{i=0}^{n} C_{i, n}-C_{i, n+1-i}
$$

The algorithm proposed by Bornhuetter and Ferguson (1972) is a deterministic method that combines the chain ladder method with the expected loss ratio indicator - a measure of exposure that relates incurred indemnities with the premium earned in each risk - for estimating the final amount of reported claims for each occurrence period i. Mano and Pereira (2009) mention that two parameters are needed to apply the Bornhuetter and Ferguson method: the reporting pattern of claims and the expected claims. The development pattern is obtained directly using the chain ladder method, while expected claims can be defined based on verified claims, relating the cumulative reported claims from the run-off triangle with the premium earned, executing adjustments in the claims in line with the tendency observed in more mature occurrence periods and the company's knowledge regarding the evolution of its business. Expected claims can also be defined based on market benchmarks.

The estimate of the final claims amount is therefore defined by equation 10 below.

$$
C_{i, n_{B F}}=\alpha_{i} \cdot \pi_{i} \cdot\left(1-\frac{1}{\hat{f}_{k}}\right),
$$

in which $\alpha_{i}$ and $\pi_{i}$ represent, respectively, the expected claims and the premium earned for each occurrence period $i$. The $\hat{f}_{k}$ term is the cumulative development factor, obtained by equation 7 . Thus, the IBNR reserve, using the Bornhuetter and Ferguson method, will be given by

$$
\widehat{R}=\sum_{i=0}^{n} C_{i, n_{B F}}-C_{i, n+1-i}
$$

The Mack (1993) method estimates the parameters of the distribution around the "best estimate" of the claims reserve, assuming that the chain ladder method generates this best estimate. The following assumptions are considered:

I. For all the occurrence periods, the cumulative amount of expected claims in development period $n$ is equal to the product of the amount of claims in $n-1$ multiplied by the development factor in the interval $n-1$ up to $n$. This factor is the historical weighted average of the occurrence periods

$$
\hat{f}_{k}=\frac{\sum_{i=1}^{n-k} c_{i, k+1}}{\sum_{i=1}^{n-k} c_{i, k}}
$$

II. The claims amounts from different occurrence periods are independent;

III.The variability of the development factors in an interval of periods is inversely proportional to the magnitude of the amounts of claims at the start of the interval.

Note that the first two assumptions are analogous to the fundamental assumptions of the chain ladder method and the third is an implicit result of this same method.

Considering these three assumptions, the standard deviation (mean square error - mse) of the claims reserve is calculated for each occurrence period $\left[\widehat{m s e\left(R_{l}\right)}\right]$ and for the total of the reserve $[m s e(\hat{R})]$.

It is proven (Mack, 1993) that:

$$
\left.\widehat{m s e\left(R_{l}\right.}\right)=m s e\left(C_{i, n}\right),
$$

that is, the average squared error of the claims reserve for occurrence period $i$ is equal to the average squared error of the final claims amount $C_{i, n}$. Thus, $\widehat{m s e\left(R_{l}\right)}$ is given by:

$$
\widehat{m s e\left(R_{l}\right)}=\hat{C}_{i, n}^{2} \sum_{k=n+1-i}^{n-1} \frac{\widehat{\sigma}_{k}^{2}}{\hat{f}_{k}^{2}}\left(\frac{1}{\hat{c}_{i, k}}+\frac{1}{\sum_{j=1}^{n-k} c_{j, k}}\right),
$$

in which

$$
\hat{\sigma}_{k}^{2}=\frac{1}{n-k-1} \sum_{i=n}^{n-k} C_{i, k}\left(\frac{C_{i, k+1}}{C_{i, k}}-\hat{f}_{k}\right)^{2}, 1 \leq k \leq n-2
$$

is an unbiased estimator of the variance of the total amount of cumulative claims $C_{i, k}$ and

$$
\hat{C}_{i, k}=C_{i, n+1-i} \hat{f}_{k-I}, k>n+1-i
$$

are the estimated values of the total amount of cumulative claims. 
For the total of the reserve, the average squared error is estimated differently, due to the structure of correlations between the estimators $\hat{f}_{k}$ and $\hat{\sigma}_{k}$. Its value is estimated by:

$$
\operatorname{mse}(\hat{R})=\sum_{i=2}^{n}\left\{\left(\operatorname{se} .\left(\hat{R}_{i}\right)\right)^{2}+\hat{C}_{i, n}\left(\sum_{j=i+1}^{n} \hat{C}_{j, n}\right) \sum_{k=n+1-i}^{n-1} \frac{2 \hat{\sigma}_{k}^{2} / \hat{f}_{k}^{2}}{\sum_{n=1}^{n-k} C_{n, k}}\right\},
$$

in which s.e. $\left(\hat{R}_{i}\right)$ represents the standard error of the claims reserve for each occurrence period.

In this paper, confidence intervals will be obtained based on the microdata available, in order to obtain the dimensioning quality measure, which will be done using bootstrapping. Bootstrapping is an iterative procedure that generates an empirical distribution of probabilities for the claims reserve and, using resampling simulations, it is possible to project alternative triangles considering the variability present in the original run-off triangle.

According to the methodology described by England and Verrall (2002), the bootstrapping process consists of taking the development factors of the cumulative reported claims triangle, maintaining the last diagonal (known amount of the reported claims up to period " $n$ "), and reestimating the values of previous occurrence and reporting periods using simulations in the incremental claims. Next, the Pearson residuals are calculated as the difference between the originally observed triangle and the reestimated triangle, as according to equation 18 ,

$$
r_{i k}^{(p)}=\frac{c_{i k}-\overline{m_{l k}}}{\sqrt{\overline{m_{l k}}}}
$$

in which $\widehat{m_{l k}}$ is the estimate of the values of incremental reported claims obtained in the $\mathrm{p}$-th round of the bootstrapping process, so that the residual is standardized, free of scale, and therefore derived from a hypothetical probability distribution. Next, as according to equation 19 , a scale parameter is calculated for the Pearson residuals, so that the scale is returned to obtain the new random triangles.

$$
\varphi=\frac{\sum_{i, j k-i+1}\left(r_{i k}^{(p)}\right)^{2}}{\frac{1}{2} n(n+1)-2 n+1}
$$

which represents the sum of the squared Pearson residuals divided by the degrees of freedom, dimensioned by the number of observations subtracted from the quantity of estimated parameters.

Finally, the Pearson residuals are adjusted using equation 20 ,

$$
r_{i k}^{(a d j)}=\sqrt{\frac{n}{\frac{1}{2} n(n+1)-2 n+1}} \cdot r_{i k}^{(p)},
$$

to replicate the bias correction using an analytical approach.

The Pearson residuals are chosen with reposition, thus generating various residuals triangles. Then based on the residuals triangles, new reported claims triangles are built, including the estimate of the final claims amount and the reserve estimate. This process is repeated $n$ times ( $n=10,000$, for example) and the set of results generated will form the empirical distribution.

\section{ANALYSIS AND INTERPRETATION OF THE RESULTS}

Based on the reported claims data, run-off triangles were built for the Motor Hull and MTPL portfolios distributed into 48 monthly occurrence periods. Figure 2 shows the known amount of claims reported to the insurer in each occurrence period (diagonal of the cumulative run-off triangle, defined in equation 4).

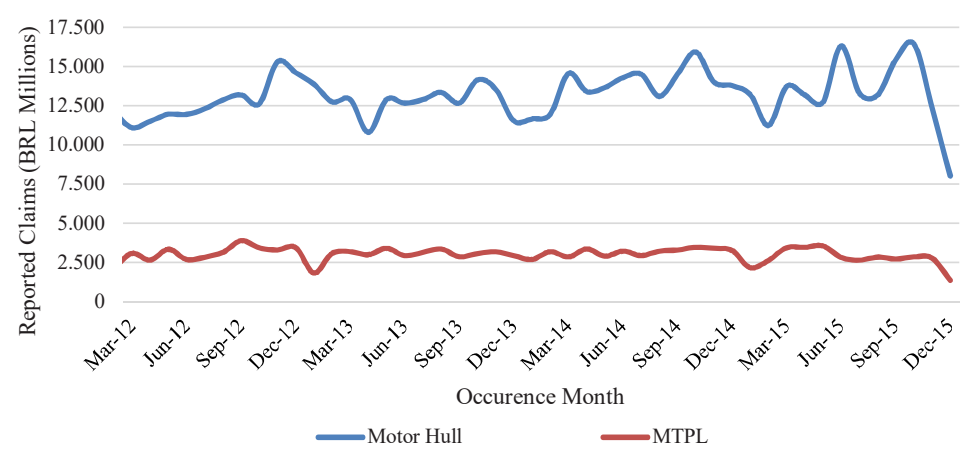

Figure 2 Evolution of the cumulative amount of reported claims per occurrence period MTPL = Motor Third Party Liability.

Source: Elaborated by the authors. 
It is verified that for the Motor Hull portfolio, the severity of the claims reports is greater in relation to the MTPL portfolio. For the occurrence periods at the end of 2015 , there is a decrease in the amount of reported claims because these claims cohorts are underdeveloped, that is, very close to the base date of the analyses, December $31^{\text {st }}$ of 2015, and there is not the completeness of the reports from previous months.

Figure 3 presents the development patterns that will serve as the basis for calculating the IBNR reserve, according to the chain ladder and Bornhuetter and Ferguson methods described in the previous section.

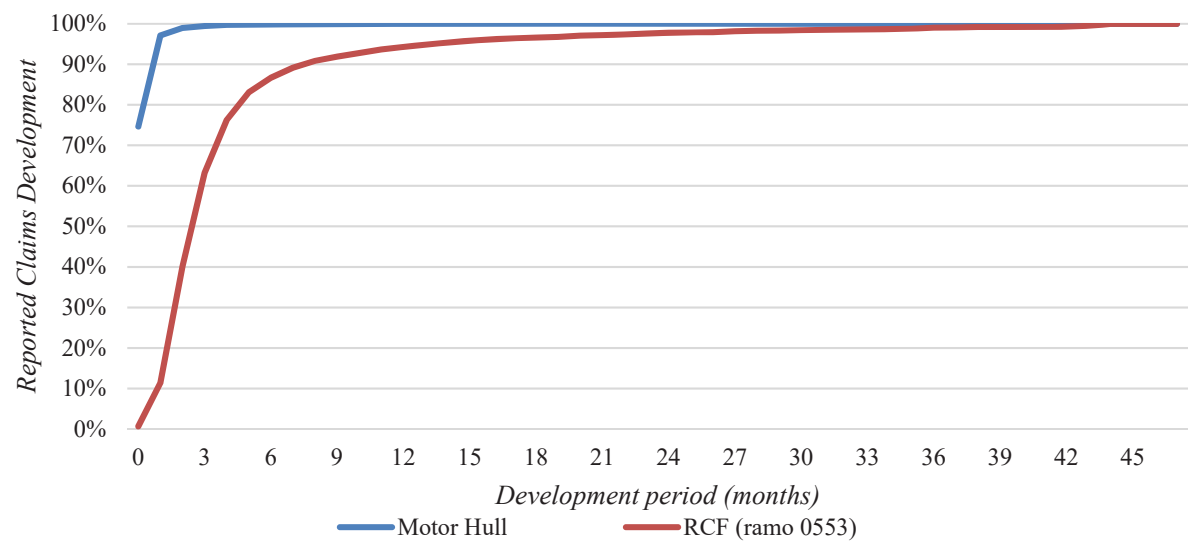

Figure 3 Claims report temporal development with development factors generated by the weighted average MTPL = Motor Third Party Liability.

Source: Elaborated by the authors.

In the Motor Hull insurance, the claims report to the insurer occurs, on average, in three months, which is explained by the insured party's interest in obtaining the indemnity guaranteed by the policy to recover full use of their car as quickly as possible. In contrast, in the MTPL portfolio - insurance in which the entity is obliged to reimburse the insured party the indemnity the former is obliged, judicially or extra-judicially, to pay as a result of involuntary damage caused to third parties - the reports develop more slowly, reaching a report maturity level in two years (24 months), primarily due to the claims that during the regulation process become legal disputes.

Figures 4 and 5 present the results of the stochastic modeling using bootstrapping. Figure 4 shows the point values of the IBNR reserve for each simulation and Figure 5 has the empirical probability distributions obtained for each one of the portfolios considered.

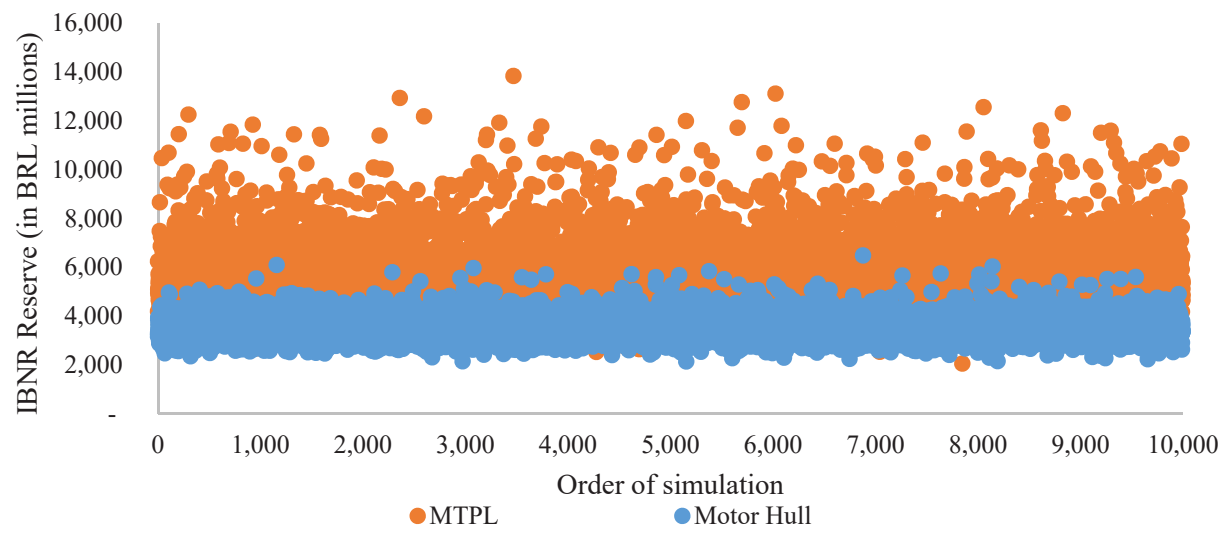

Figure 4 Point estimates of the incurred but not reported (IBNR) reserves reestimated using bootstrapping, considering 10 thousand iterations MTPL = Motor Third Party Liability.

Source: Elaborated by the authors. 


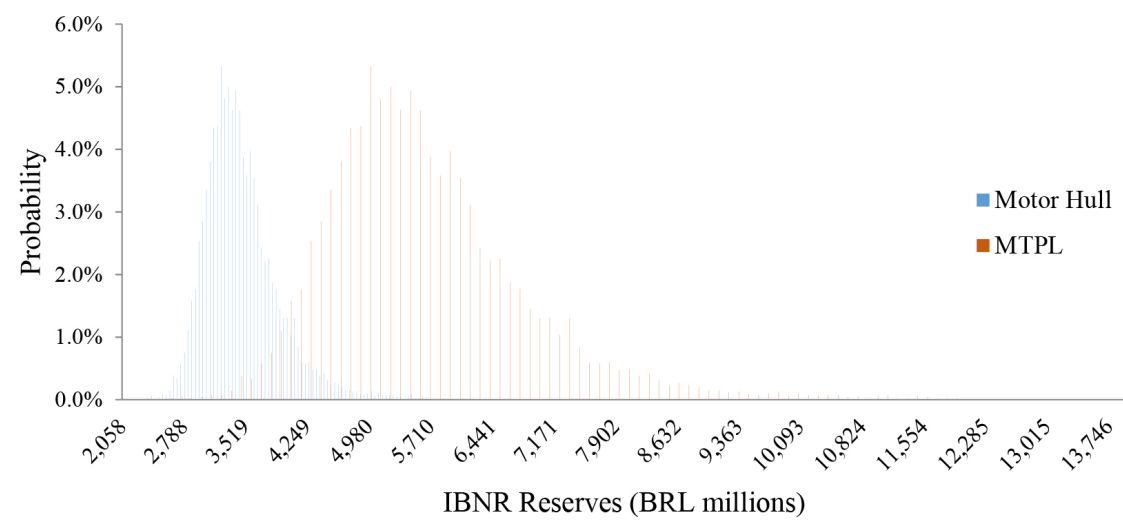

Figure 5 Stochastic probability distribution of the incurred but not reported (IBNR) reserve - Motor Hull and Motor Third Party Liability (MTPL) insurance portfolios

Source: Elaborated by the authors.

Table 2

Descriptive statistics of the empirical distributions obtained by bootstrapping - values in BRL thousands

\begin{tabular}{lcc}
\hline Statistic & Motor Hull & MTPL \\
\hline Minimum value & 2,146 & 2,059 \\
\hline Maximum value & 6,486 & 13,839 \\
\hline Average value & 3,522 & 5,605 \\
\hline Standard deviation & 430 & 1,210 \\
\hline Coefficient of variation $(\%)$ & 12.2 & 21.6 \\
\hline Kurtosis & 0.12 & 3.17 \\
\hline Convergence $(\%)$ & 100.0 & 99.8 \\
\hline
\end{tabular}

MTPL $=$ Motor Third Party Liability.

Source: Elaborated by the authors.
The arrangement of the point estimates in Figure 4 reveals the greater volatility experienced by MTPL, caused primarily by its longer temporal development pattern. This is supported by the probability distribution presented in Figure 5, in which the fatter tail to the right stands out (leptokurtosis; kurtosis $=3.17$ ). The probability function of the Motor Hull segment indicates similar behavior to the normal distribution, with a standard deviation representing the symmetry around the average value well. The "Convergence" index indicates, for the two portfolios studied, the assertiveness between the simulated average values and the value of the deterministic best estimate obtained via chain ladder.

Table 3 presents the results of the value of the IBNR reserve considering four methods, two deterministic and two stochastic. The relative differences of each method are also shown in relation to the best estimate generated using the chain ladder method.

Table 3

Results of calculating the incurred but not reported (IBNR) reserve estimated using the deterministic and stochastic methods values in BRL thousands

\begin{tabular}{|c|c|c|c|c|c|}
\hline \multirow[t]{2}{*}{ Method } & \multirow[t]{2}{*}{ Type } & \multicolumn{2}{|c|}{ IBNR Reserve } & \multicolumn{2}{|c|}{$\begin{array}{l}\text { Relative difference in relation to the best } \\
\text { estimate } \\
(\%)\end{array}$} \\
\hline & & Motor Hull & MTPL & Motor Hull & MTPL \\
\hline $\begin{array}{l}\text { Chain ladder (best } \\
\text { estimate) }\end{array}$ & Deterministic & 3,524 & 5,594 & - & - \\
\hline $\begin{array}{l}\text { Bornhuetter and } \\
\text { Ferguson }\end{array}$ & Deterministic & 3,391 & 5,446 & -3.8 & -2.6 \\
\hline $\begin{array}{l}\text { Bootstrapping } \\
\text { empirical } \\
\text { distribution (50\% } \\
\text { percentile) }\end{array}$ & Stochastic & 3,488 & 5,412 & -1.0 & -3.3 \\
\hline $\begin{array}{l}\text { Log-normal } \\
\text { distribution }(50 \% \\
\text { percentile) }\end{array}$ & Stochastic & 3,454 & 5,400 & -2.0 & -3.5 \\
\hline
\end{tabular}

MTPL $=$ Motor Third Party Liability.

Source: Elaborated by the authors. 
It is observed that, in general, there are few divergences between the values of the point estimates generated using the deterministic methods and those calculated using stochastic processes. This is expected, since two lines of business that have a large volume of information are concerned, which guarantees strong result stability. The Bornhuetter and Ferguson (1972) method generates smaller estimates, since it leads to adjustments to the most recent occurrence periods, according to the exposure measured by the expected loss ratio indicator. Note, also, that the bootstrapping empirical distribution generates similar estimates to those of a log-normal distribution.

Table 4 presents the results of the main statistical metrics generated by applying the Mack (1993) model and by the bootstrapping process. The objective of this table is to show the uncertainty inherent to the IBNR reserve measured using the standard error proposed by Mack, as well as by the standard deviation obtained by the bootstrapping empirical distribution. Based on these uncertainty measures, upper and lower limits are obtained that can be understood as the interval of possible scenarios for the reserve.

Table 4

Results of applying the Mack (1993) and bootstrapping model - values in BRL thousands

\begin{tabular}{lcccc}
\hline \multirow{2}{*}{ Metric } & \multicolumn{2}{c}{ Motor Hull } & \multicolumn{2}{c}{ MTPL } \\
\cline { 2 - 5 } & $\begin{array}{c}\text { Mack } \\
\mathbf{( 1 9 9 3 )}\end{array}$ & Bootstrapping & $\begin{array}{c}\text { Mack } \\
\mathbf{( 1 9 9 3 )}\end{array}$ & Bootstrapping \\
\hline $\begin{array}{l}\text { Total } \\
\text { standard } \\
\text { error }\end{array}$ & 712 & 430 & 1,513 & 1,210 \\
\hline $\begin{array}{l}\text { Total } \\
\text { standard } \\
\text { error }(\%)\end{array}$ & 20.2 & 12.2 & 27.1 & 21.6 \\
\hline
\end{tabular}

MTPL $=$ Motor Third Party Liability.

Source: Elaborated by the authors.

Comparing the results obtained for the two portfolios under analysis, given the greater volatility of MTPL, it is verified that its standard error is more than double using the Mack (1993) method and almost triple using bootstrapping, when compared to the data from the Motor Hull segment. Consequently, the confidence interval for MTPL has a greater amplitude, both from the viewpoint of the Mack (1993) model and via bootstrapping. For the Motor Hull portfolio, given its stable behavior, the confidence interval of the best estimate will be more constrained. The results are presented in Table 5.

\section{Table 5}

Confidence interval for the best estimate of the IBNR reservevalues in BRL thousands

\begin{tabular}{lcccc}
\hline \multirow{2}{*}{ Method } & Segment & \multicolumn{3}{c}{ Confidence interval } \\
\cline { 2 - 5 } & $\begin{array}{c}\text { Lower } \\
\text { limit }\end{array}$ & $\begin{array}{c}\text { Best } \\
\text { estimate }\end{array}$ & $\begin{array}{c}\text { Upper } \\
\text { limit }\end{array}$ \\
\hline \multirow{2}{*}{ Mack (1993) } & Motor Hull & 2,812 & 3,524 & 4,236 \\
\cline { 2 - 5 } & MTPL & 4,081 & 5,594 & 7,108 \\
\hline \multirow{2}{*}{ Bootstrapping } & Motor Hull & 3,091 & 3,524 & 3,952 \\
\cline { 2 - 5 } & MTPL & 4,395 & 5,594 & 6,815 \\
\hline
\end{tabular}

MTPL = Motor Third Party Liability.

Source: Elaborated by the authors.

In both portfolios under analysis, the bootstrapping empirical distribution generates a smaller standard error than that calculated using Mack (1993); that is, using bootstrapping, the confidence interval for the best estimate is more constrained. This occurs because the bootstrapping procedure captures a greater quantity of possible scenarios, considering the original run-off triangle and $n=10,000$ simulated alternative triangles. In contrast, the Mack (1993) method concentrates only on the variability inherent to the original triangle.

The interpretation of Table 5, from the viewpoint of the actuarial analyst, is that the best estimate of the IBNR reserve (or any other technical provision that involves the chain ladder method) can vary, but within an acceptable interval. A reserve value below the lower limit indicates an insufficiency of reserve - which can negatively affect the insurer's solvency, depending on the relevance of the portfolio under analysis in its liabilities. A value above the upper limit indicates an excessive reserve, which can compromise the company's operational profit.

From the actuarial auditor's viewpoint, the principle is analogous. Applying a confidence interval in their technical provision review work enables the validation of numbers that may not represent the reality of the entity audited. If in their auditing work reserve values are verified that are outside a confidence interval, this raises questions about the entity's management and its causes can be investigated. In addition, situations may be found of fraudulent technical provisions accounting to manage operational earnings or for tax management purposes, as well as insufficient technical provisions with a negative impact on the insurer's solvency indicators.

It is important to highlight that the proposed limits indicate a confidence interval; that is, given the uncertainty that the calculation of technical provisions for claims is subject to - since the IBRN reserve represents indemnities that will come to the attention of the insurer, and this 
is a random variable with an unknown distribution this interval aims to cover the possible scenarios for the value of the reserve amount. Thus, the lower and upper limits may be understood as values calculated in order to indicate a risk measure - of insufficient funds - in the entity's balance sheet.

The confidence interval proposed provides a view of what is acceptable at the time of constituting the reserve. However, it matters for the insurer's management, and also for the actuarial auditors, to understand what capital value is needed to cover the volatility of the technical provisions that derives from the risk underwriting process. Another relevant question is: how can it be guaranteed that the deterministic IBNR is sufficient to cover the events that the insurer is not yet aware of? Deterministic methods do not provide answers to these questions. Considering these points, figures 6 and 7 present the comparative analysis between the deterministic reserve values and the values associated with the quantiles of the empirical (bootstrapping) and log-normal distributions for both lines of business evaluated. The log-normal distribution was chosen as it is a distribution that represents two important characteristics of the events modeled here: first because it is a distribution that is truncated at zero, guaranteeing that there are no negative value claims; second, because this is a distribution that is asymmetric to the right, configuring an appropriate distribution for adjusting events that may have excess damage. Moreover, as the Central Limit Theorem guarantees that, in largesized samples, as is the case of this study, the sampling distribution (empirical, via bootstrapping) of its average is close to a Normal distribution, there is an effective comparison of the sensitivity in the reserves due to the fact that the claims can have a kurtosis that is beyond Normal.

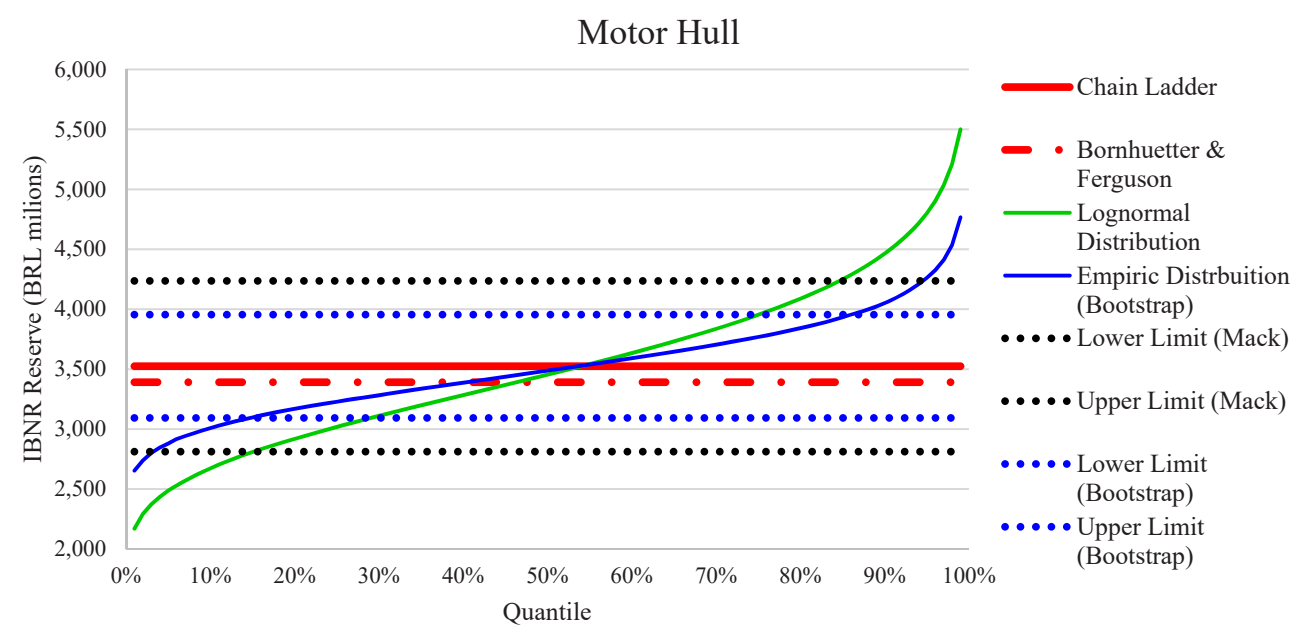

Figure 6 Comparative analysis of the results generated using the deterministic methods and the stochastic modeling - Motor Hull insurance portfolio

IBNR = incurred but not reported.

Source: Elaborated by the authors.

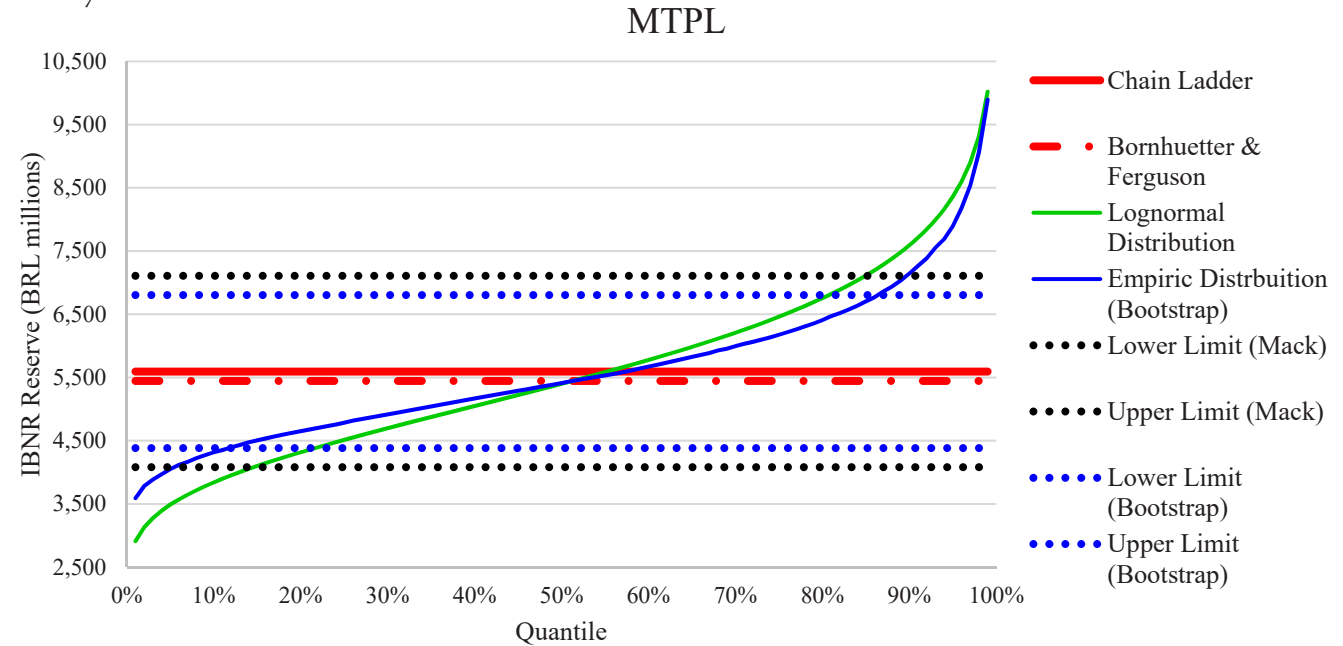

Figure 7 Comparative analysis of the results generated using the deterministic methods and the stochastic modeling - Motor Third Party Liability (MTPL) insurance portfolio

IBNR = incurred but not reported.

Source: Elaborated by the authors. 
Table 6

Quantiles of the empirical and log-normal distributions corresponding to the limits generated by Mack (1993) - values in BRL thousands

\begin{tabular}{llccc}
\hline \multirow{2}{*}{ Portfolio } & Confidence interval (Mack) & $\begin{array}{c}\text { Corresponding quantile } \\
\text { (bootstrapping) } \\
(\%)\end{array}$ & $\begin{array}{c}\text { Corresponding quantile } \\
\text { (log-normal) } \\
(\%)\end{array}$ & 3 \\
\hline \multirow{2}{*}{ Motor Hull } & Lower limit & 2,812 & 94 & 15 \\
\hline \multirow{2}{*}{ MTPL } & Upper limit & 4,236 & 5 & 84 \\
\cline { 2 - 5 } & Lower limit & 4,081 & 89 & 14 \\
\hline
\end{tabular}

MTPL $=$ Motor Third Party Liability.

Source: Elaborated by the authors.

Table 7

Comparative analysis of the quantiles of the empirical distribution in relation to the limits generated by Mack (1993) - values in BRL thousands

\begin{tabular}{|c|c|c|c|c|c|}
\hline Portfolio & $\begin{array}{c}\text { Quantile } \\
(\%)\end{array}$ & $\begin{array}{c}\text { IBNR reserve } \\
\text { (bootstrapping) }\end{array}$ & $\begin{array}{l}\text { Lower and upper } \\
\text { limits (Mack) }\end{array}$ & Difference & $\begin{array}{l}\text { Relative difference } \\
\qquad(\%)\end{array}$ \\
\hline \multirow{6}{*}{ Motor Hull } & 1 & 2,653 & 2,812 & -158.8 & -5.65 \\
\hline & 99 & 4,766 & 4,236 & 530.2 & 12.52 \\
\hline & 5 & 2,880 & 2,812 & 67.6 & 2.40 \\
\hline & 95 & 4,261 & 4,236 & 25.1 & 0.59 \\
\hline & 10 & 3,008 & 2,812 & 196.1 & 6.97 \\
\hline & 90 & 4,050 & 4,236 & -185.1 & -4.37 \\
\hline \multirow{6}{*}{ MTPL } & 1 & 3,590 & 4,081 & -490.9 & -12.03 \\
\hline & 99 & 9,896 & 7,108 & $2,787.9$ & 39.22 \\
\hline & 5 & 4,050 & 4,081 & -31.2 & -0.77 \\
\hline & 95 & 7,895 & 7,108 & 787.5 & 11.08 \\
\hline & 10 & 4,317 & 4,081 & 235.7 & 5.78 \\
\hline & 90 & 7,146 & 7,108 & 38.3 & 0.54 \\
\hline
\end{tabular}

MTPL $=$ Motor Third Party Liability.

Source: Elaborated by the authors.

Evaluating figures 6 and 7 and tables 6 and 7 together, we can verify the implicit measure that the balance sheet does not report regarding the technical provisions: the probability of there being a lack of funds to honor commitments to the insured, even after the realistic addition of accounting expenses. While the Mack (1993) method only considers past occurrences to estimate the load over the technical provisions, the bootstrapping method simulates situations that could have occurred based on events that have already happened. Estimating the probability distribution of all possibilities, it is possible to extract the probability measure of capital insufficiency that the Mack (1993) method does not provide.

Table 6 presents the intersections of the upper limits estimated using the Mack (1993) method of figures 6 and 7. Adopting the Motor Hull segment as an example, the estimated probability, according to the Mack (1993) method, of the real value of the IBNR reserve exceeding
$\mathrm{R} \$ 4.3$ million is $6 \%$. When the theoretical parametric (log-normal) distribution is imposed, the Mack (1993) method would provide a value whose probability of incurring capital insufficiency would be $16 \%$. This is also expected to the extent that imposing a theoretical distribution may not be inherent to the observed data.

Due to the Mack (1993) model adopting the premise of symmetry around the best estimate of the technical provisions, that is, the incurred volatility in the case of hypo or hypersufficiency of the reserves having the same magnitude, then the limits of the confidence interval generated may cover fewer possible scenarios than the empirical distribution, since its method does not define, at any point, the confidence level of its interval. This is particularly serious when faced with leptokurtic distributions (such as that of the MTPL segment) or asymmetric ones (in both cases considered there is asymmetry to the right). 
Table 7 details what the alteration (relative difference) should be in the limits calculated using Mack that would generate confidence intervals of 90,95 , and $99 \%$. The effects on the Mack limits are more severe increases in the upper limits than the reductions in the lower limits for both insurance segments, revealing, once again, that asymmetric distributions to the right are concerned and that MTPL has a fatter tail to the right than Motor Hull.

The analysis of the quantiles corresponding to the limits generated using Mack (1993) shows that, in general, the log-normal (parametric) distribution is more conservative than the empirical distribution. This reveals that the stochastic modeling considers that the possibilities of a variation are more constrained for the same confidence level, showing the assertiveness of the method.

Therefore, the main advantage of bootstrapping when compared to the model proposed by Mack (1993) is that in Mack there is no clear notion regarding which confidence levels (scenarios) are contemplated by the limits. Another advantage of bootstrapping is that the empirical distribution reveals the estimated probability of the real value exceeding that level of reserve.

\section{CONCLUDING REMARKS}

This paper sought to achieve two main objectives: (i) to obtain a variability measure for the claims reserves estimated using the chain ladder method in order to build a confidence interval for the best estimate of technical provisions, providing additional parameters for actuarial decision making; and (ii) to evaluate in what way adopting stochastic models can generate additional information about claims reserves.

The proposed objectives were achieved considering the Mack (1993) models and the application of the bootstrapping method, via which a confidence interval was calculated for the deterministic estimates of the IBNR reserve (presented in Table 5), using real data from a Brazilian insurer and analyzing two portfolios, Motor Hull and MTPL. Also via bootstrapping, the empirical probability distributions for the IBNR reserve were calculated (figures 5, 6, and 7), which generated additional information about the quantiles associated with the reserve. The quantiles report the estimated probability of the real value exceeding a particular level of reserve.

Comparing the results generated using Mack (1993) and bootstrapping indicates that there are advantages in adopting the simulations using bootstrapping: the simulations generated via bootstrapping reflect situations that could have happened given the events already occurred. On the other hand, via bootstrapping, by estimating the empirical probability distribution and its quantiles, it is possible to extract the probability measure of capital insufficiency or sufficiency that the Mack (1993) method does not provide.

The stochastic modeling using bootstrapping, when applied to occurred and unpaid claims data, will indicate what capital value is needed to cover the volatility of the technical provisions for claims, as well as the probability of incurring capital insufficiency. That is, the stochastic approach enables internal models of additional capital based on underwriting risk to be studied. This is a topic that lacks studies in the Brazilian insurance market, in which additional capital based on underwriting risk is determined by a standard model defined by SUSEP, but where it is necessary to estimate the aggregate probability distribution for all the lines of business in which the insurer underwrites risks. In general, a safety load over the technical provisions is used, which is calculated using a normal approximation of the aggregated claim. But it is possible to resort to copula theory, which models the multivariate structure of dependency between various lines of business. When the correlation is incorporated, it is possible to reduce the need to constitute a capital reserve based on underwriting risk.

The models proposed in this paper use past data to calculate projections. So, they are subject to limitations due to factors such as unexpected alterations in business volume, changes in product design and underwriting policies, among others. It is essential, with the passing of time and new available information, perform consistency tests to guarantee the adherence of the models to the reality of the entity's operations.

Moreover, studying the variability of the technical provisions and measuring margins of risk imply evaluations of the variability of the insurance entities' operational profit. By doing so, the understanding of the impact of fluctuations in the technical provisions on the value allocated in net equity becomes clearer, thus providing a crucial element for modern actuarial management and for transparency in the disclosure of results. All these aspects (measurement, accounting, corporate governance mechanisms, and disclosure) will gain relevance, especially with the advent of the Solvency II agreement, in Europe, and with the new guidelines for recording insurance contracts issued in the International Financial Reporting Standards (IFRS, 
2017), which is currently in the stage of being adopted by regulatory entities and will come into effect from 2021 onwards.

In Brazil, despite the low frequency of use of stochastic approaches in insurers, the tendency is for this topic to shortly gain relevance, given the need of foreign insurers, with branches registered at SUSEP, to consolidate their financial statements within the molds of Solvency II and IFRS. Thus, stochastic modeling may cease to be merely a supporting instrument, as it is today, and become a sine qua non condition for more comprehensively evaluating the solvency situation of Brazilian insurers.

\section{REFERENCES}

Actuarial Standards Board. (2010). Actuarial Standard of Practice n. 36. Statements of actuarial opinion regarding property/ casualty loss and loss adjustment expense reserves. Retrieved from http://www.actuarialstandardsboard.org/asops/ statements-actuarial-opinion-regarding-propertycasualtyloss-loss-adjustment-expense-reserves/.

Actuarial Standards Board. (2011). Actuarial Standard of Practice n. 43. Property/casualty unpaid claim estimates. Retrieved from http://www.actuarialstandardsboard.org/asops/ propertycasualty-unpaid-claim-estimates/.

Bornhuetter, R. L., \& Ferguson, R. E. (1972). The actuary and IBNR. Proceedings of the Casualty Actuarial Society, LIX, 181195.

Circular Superintendência de Seguros Privados (Superintendence of Private Insurance Bulletin) n. 517/2015. Describes technical provisions; liability adequacy test; reductive assets; underwriting risk capital; credit, operational and market; constitution of operating losses database; solvency regularization plan; recording, custody, and movement of assets and securities guaranteeing technical provisions; Periodic Information Form - FIP/SUSEP; Accounting Standards and independent accounts auditing of insurers, open-ended complementary pension funds, capitalization companies, and reinsurers; certification exam and continuous professional training of the independent accounts auditor; and the Technical Pronouncements elaborated by the Brazilian Actuarial Institute - IBA. Retrieved from http://www2.susep.gov.br/bibliotecaweb/docOriginal. aspx? tipo $=1 \&$ codigo $=35656$.

Directive of the European Parliament and of the Council. (2009). Directive 2009/138/EC of the European Parliament and of the Council of 25 November 2009 on the taking-up and pursuit of the business of Insurance and Reinsurance (Solvency II). Retrieved from http://eur-lex.europa.eu/legal-content/EN/ ALL/?uri=OJ:L:2009:335:TOC.

Dreksler, S., Allen, C., Akoh-Arrey, A., Courchene, J. A., Junaid, B., Kirk, J., Lowe, W., O’Dea, S., Piper, J., Shah, M., Shaw, G., Storman, D., Thaper, S., Thomas, L., Wheatley, M., \& Wilson, M. (2015). Solvency II technical provisions for general insurers. British Actuarial Journal, 20(1), 7-129.

England, P. D., \& Verrall, R. J. (2002). Stochastic claims reserving in general insurance. British Actuarial Journal, 8(3), 443-518.

England, P. D., \& Verrall, R. J. (2006). Predictive distributions of outstanding liabilities in general insurance. Annals of Actuarial Science, 1(2), 221-270.
Hachemeister, C. A., \& Stanard, J. N. (1975). IBNR claims count estimation with static lag functions. In Annals of 12th ASTIN Colloquium, International

Actuarial Association (pp. 1-23). Portimao, Portugal.

International Actuarial Association. (2016). Non-life reserving practices. Report $n$. 1. Retrieved from http://www.actuaries. org/ASTIN/Documents/ASTIN_WP_NL_Reserving Report1.0_2016-06-15.pdf.

International Financial Reporting Standards. (2017). IFRS 17 insurance contracts. Retrieved from http://www.ifrs. org/issued-standards/list-of-standards/ifrs-17-insurancecontracts/.

Mack, T. (1993). Distribution free calculation of the standard error of chain ladder reserve estimates. ASTIN Bulletin, 23(2), 213-225.

Mano, C. C. A., \& Pereira, P. P. (2009). Aspectos atuariais e contábeis das provisões técnicas. Rio de Janeiro: Funenseg.

Resolução Conselho Nacional de Seguros Privados (National Council of Private Insurance Resolution) n. 311/2014. (2014). Describes the provision of independent actuarial auditing services to insurance comapnies, open-ended complementary pension funds, capitalization companies, and local reinsurers. Retrieved from http://www2.susep.gov.br/bibliotecaweb/ docOriginal.aspx?tipo $=1 \&$ codigo $=33083$.

Resolução Conselho Nacional de Seguros Privados (National Council of Private Insurance Resolution) n. 321/2015. (2015). Describes technical provisions; assets that reduce the need for coverage of technical provisions; risk capital based on underwriting risks, credit, operational and market; adjusted net equity; minimum capital required; solvency regularization plan; retention limits; criteria for making investments; accounting standards; accounts auditing and independent actuarial auditing; and Auditing Committees relating to insurers, open-ended complementary pension funds, capitalization companies, and reinsurers.

Resolução Instituto Brasileiro de Atuária (Brazilian Actuarial Institute Resolution) n. 5/2014. (2014). Describes the creation of CPA Actuarial Pronouncement 002 - INDEPENDENT ACTUARIAL AUDITING OF ENTITIES SUPERVISED BY SUSEP. Retrieved from http://www.atuarios.org.br/docs_old/ Arq635475964046568203.pdf.

Schiegl, M. A. (2015). A model study about the applicability of the chain ladder method. Scandinavian Actuarial Journal, 2015(6), 1-25. 
Schmidt, K. D. (2006). Methods and models of loss reserving based on run-off triangles: A unifying survey. In Proceedings of Casualty Actuarial Society Forum (section 3, pp. 269-317). Atlanta, United States of America.

Shapland, M. R. (2003). Loss reserve estimates: A statistical approach for determining "reasonableness". In Proceedings of CAS Forum (pp. 321-360). New Orleans, United States of America.
Tarbell, T. F. (1934). Incurred but not reported claim reserves. Proceedings of the Casualty Actuarial Society, XX, 275-280.

Taylor, G., \& Mcguire, G. (2016). Stochastic loss reserving using generalized linear models. Arlington: Casualty Actuarial Society.

Weindorfer, B. (2012). A practical guide to the use of the chainladder method for determining technical provisions for outstanding reported claims in non-life insurance [Technical Report]. University of Applied Sciences of Vienna. 